\title{
CORONELISMO E GAMONALISMO SOB UMA PERSPECTIVA DIALÉTICA ${ }^{1}$
}

\section{Colonelism and gamonalism under a dialectical perspective}

Pedro Gabriel V. Heráclio do Rego ${ }^{2}$

RESUMO: Este trabalho tem por objetivo analisar as dinâmicas de funcionamento dos fenômenos sócio-políticos conhecidos como coronelismo e gamonalismo, levando em consideração os estudos concernentes a este tema feitos por Caio Prado Júnior e José Carlos Mariátegui, entre outros autores. Representações dos respectivos fenômenos em obras de ficção serão usadas como suporte à análise.

Palavras-chave: Coronelismo. Gamonalismo. Representação ficcional.

ABSTRACT: This work aims to analyze the functioning dynamics regarding the social and political phenomena known as coronelismo and gamonalismo, taking into account the studies regarding this theme conducted by Caio Prado Junior and Jose Carlos Mariátegui, among other authors. Fictional representation of the respective phenomena will be used as analysis support.

Keywords: Coronelismo. Gamonalismo. Fictional representation.

\section{INTRODUÇÃO}

O mandonismo se trata de um fenômeno típico brasileiro, no qual a permanência de uma estrutura social baseada no latifúndio e na família extensa num contexto pós-independência. A atitude do chefe político local era primordial para qualquer decisão de cunho econômico, político, social ou mesmo de burocracia estatal. O coronelismo significa um aspecto específico e datado desse fenômeno geral que é o mandonismo, localizado no Nordeste brasileiro, que ganhou força com a criação da Guarda Nacional, evento que permitiu a esses proprietários rurais transformarem-se em chefes militares.

\footnotetext{
${ }^{1}$ Trabalho apresentado como requisito para aprovação na disciplina Pensamento Latino-americano, ministrada pelo Prof. Dr. Alfredo Cordiviola.

${ }_{2}$ Mestre em Teoria da Literatura pelo Programa de Pós-graduação em Letras da Universidade Federal de Pernambuco.
} 
Esta estrutura de poder remonta à grande propriedade monocultural trabalhada por escravos, como observa Caio Prado Júnior em sua Formação do Brasil Contemporâneo (1942). Para Caio Prado Júnior, essa modalidade de organização agrária "corresponde à exploração agrícola em larga escala, em oposição à pequena exploração do tipo camponês" (PRADO JÚNIOR, 1976, p. 119), e foi inevitável dadas as "contingências fatais criadas pelo conjunto das condições internas e externas que acompanham a obra aqui realizada por ela" (p.119). A manutenção de algumas dessas práticas no período após a Independência, aliada a um panorama de ascensão do poder público e decadência do poder privado permitiram o estabelecimento das diversas facetas do mandonismo das quais 0 coronelismo é um dos aspectos.

Estruturas de poder similares, baseadas no latifúndio, podem ser identificadas em várias outras ambiências ao longo do território Latino-Americano, como o gamonalismo, observado no Peru, Equador e outros países. José Carlos Mariátegui escrutiniza esse fenômeno em seus Sete ensaios de interpretação da realidade peruana (1928), que tem características próprias que norteiam as divergências entre os fenômenos em países distintos - Brasil e Peru, respectivamente, no cerne da análise que conduziremos - e notáveis similitudes, por outro lado. Mariátegui discorre sobre o problema do índio e a sua organização econômica e social com tendências próximas ao socialismo - e de como o feudalismo dos gamonales entra em conflito com a sua resolução:

A questão indígena nasce de nossa economia. Tem suas raízes no
regime de propriedade de terra. Qualquer tentativa de resolvê-la com
medidas de administração ou polícia, com métodos de ensino ou
obras de estradas, constituiu um trabalho superficial ou adjetivo,
enquanto subsistir o feudalismo dos gamonales. O gamonalismo
invalida toda lei ou ordenamento de proteção indígena. O fazendeiro,
o latifundiário, é um senhor feudal. Contra a sua autoridade,
ambiente e pelo hábito, a lei escrita é impotente. O trabalho gratuito
está proibido por lei e, no entanto, o trabalho gratuito, e até o
trabalho forçado, sobrevivem no latifúndio. (MARIẢTEGUI, 2010, p.
$54-55$, grifos do autor).

Estas estruturas de poder e latifúndio estão largamente representadas em manifestações culturais e literárias, como nas obras de José Lins do Rego mormente aquelas que compõem o ciclo da cana de açúcar, demonstrando o coronelismo e a decadência dos senhores de engenho; e em Redoble por Rancas, 
de Manuel Scorza, que demonstra o modus operandi dos gamonales em seus latifúndios.

\section{FORMAÇÃO E CORONELISMO}

O coronelismo tem suas origens numa configuração local e específica do mandonismo no ambiente do Nordeste rural dos senhores de engenho e fazendeiros ligados à pecuária e plantação de algodão. Caio Prado Júnior teoriza sobre a inexorabilidade desta prática de organização econômica, social e política:

A grande exploração agrária - o engenho, a fazenda - é consequência natural e necessária de tal conjunto, resulta de todas aquelas circunstâncias que concorrem para a ocupação e aproveitamento deste território que havia de ser o Brasil: o caráter tropical da terra, os objetivos que animam os colonizadores, as condições gerais desta nova ordem econômica do mundo que se inaugura com os grandes descobrimentos ultramarinos, e na qual a Europa temperada figurará no centro de um vasto sistema que se estende para os trópicos a fim de buscar neles os gêneros que aquele centro reclama e que só eles podem fornecer. São estes, em última análise, os fatores que vão determinar a estrutura agrária do Brasil-colônia. (PRADO JÚNIOR, 1976, p. 119, grifos do autor).

Assim, a tríade composta por grande propriedade, trabalho escravo e monocultura se combina e inter-relaciona diretamente com os mencionados fatores. Manoel Bonfim explica, em seu estudo, sobre como o parasitismo, ou a exploração indiscriminada das metrópoles sobre as colônias influiu negativamente sobre a formação social, econômica, política e moral do Brasil e outros países latinoamericanos:

São os efeitos econômicos os mais sensíveis nesse regime de colonização parasitária. Pode-se mesmo dizer que são os efeitos primordiais, aos quais se ligam os outros como efeitos secundários. Em si, o parasitismo das metrópoles, como o parasitismo social em geral, é um fenômeno de ordem econômica, cujos efeitos se refletem sobre toda a vida social. Esta afirmação equivale a um truísmo. Por isto - pela importância desses efeitos econômicos - é mister insistir um pouco nos fatos que a eles se ligam. Não tanto para fazer a prova de tais fatos - evidentes por si mesmo, mas para mostrar como eles provocam os outros vícios, defeitos, anomalias e perversões, de que sofrerão as futuras nacionalidades, tanto na sua vida política, como na sua evolução moral e social; para fazer sentir bem como todas essas anomalias e vícios derivam, direta ou indiretamente, dos do parasitismo da metrópole. (BONFIM, 2008, p. 87). 
Após a Independência do Brasil, o poder municipal teria rompido o limite das pequenas vilas, por meio dos filhos, dos sobrinhos, dos afilhados e dos genros dos senhores rurais, que vivam nas grandes cidades, assegurando a hegemonia dos senhores rurais em todo o território nacional. Essa perspectiva é também abordada por Sérgio Buarque de Holanda em Raízes do Brasil (1936):

Na monarquia eram ainda os fazendeiros escravocratas e eram filhos de fazendeiros, educados nas profissões liberais, quem monopolizava a política, elegendo-se ou fazendo eleger seus candidatos, dominando os parlamentos, os ministérios, em geral todas as posições de mando, e fundando a estabilidade das instituições nesse incontestado domínio. (HOLANDA, 1956, p. 88-89).

Durante o reinado de dom Pedro II (1840-1889), os partidos políticos serviam de fachada para o domínio dos chefes locais, como observa André Heráclio do Rego em seu estudo sobre o tema, Família e coronelismo no Brasil: uma história de poder (2008):

O poder político, na transição entre o Império e a República, e ressalvando-se o período de Deodoro da Fonseca e de Floriano Peixoto, permaneceria nas mesmas mãos, visto que se havia conservado a mesma organização rural. O centro da vida política, apesar de todas as limitações estabelecidas pela lei, teria continuado a ser o coronel. A diferença seria que esse fenômeno, que durante o Império manifestava-se na sombra, havia atingido a plena luz chegada a República, tendo sido revelado pelas eleições para os governos dos Estados Federados, que exigiam do chefe da política estadual muito trabalho para a coordenação e harmonização dos coronéis das diversas áreas de influência. O governismo, a aliança com o governo, era assim uma garantia a mais para a vitória dos interesses privados, um instrumento suplementar de mando. (REGO, 2008, p. 66-67).

É importante observar a consequência do aumento do poder político-eleitoral da grande propriedade na configuração do coronelismo, mas "esse aumento, no entanto (e aí reside o paradoxo) não se deveria ao reforço do poder do latifúndio, mas, ao contrário, à sua decadência." (REGO, 2008, p.65) E diretamente ligado ao reforço do poder público frente ao poder privado, e não ao seu enfraquecimento.

Gilberto Freyre, em Nordeste: Aspectos sobre a influência da cana sobre a vida e a paisagem do Nordeste do Brasil, fala sobre a fatalidade dos meios em que se operou a colonização e a exploração da mão-de-obra escrava: 
Se elementos geneticamente tão bons como os primeiros colonos negros e os primeiros colonos brancos do Nordeste vieram a desprestigiar-se sob vários aspectos, é que sobre eles atuaram, com uma intensidade que foi maior aqui do que noutras regiões do Brasil, as influências, desfavoráveis ao homem, da cultura da cana de açúcar, quando realizada como se realizou entre nós: com exclusão de culturas de subsistência; pelo latifúndio; pela escravidão; pelo patriarcalismo monossexual, ao mesmo tempo que monocultor. Condições e meios insubstituíveis na primeira época da colonização portuguesa do Nordeste, embora pudessem ter sido atenuados depois. (FREYRE, 2004, p.149).

Caio Prado Júnior descreve, por outro lado, o tipo de colono que se estabeleceu no território brasileiro: "Não é o trabalhador, o simples povoador; mas o explorador, o empresário de um grande negócio. Vem para dirigir: se é para o campo que se encaminha, só uma empresa de vulto, a grande exploração rural em que figure como senhor pode o interessar" (PRADO JÚNIOR, 1976, p. 120). Assim, ao contrário de Freyre, demonstra os pilares constitutivos da organização agrária do Brasil colonial, que se firmará como a base em que se formará toda a estrutura econômica e social do país:

A grande propriedade lavrada por trabalhadores dependentes, sejam escravos ou assalariados, ou bem formas intermediárias de trabalho, representa o sistema de organização agrária que sempre acaba dominando nos trópicos, mesmo quando outros são inicialmente tentados. Combinam-se as dificuldades que o meio natural oferece ao trabalho de indivíduos isolados, sobretudo quando se trata ainda de desbravamento, com as exigências técnicas da exploração tropical (aparelhamento necessário, organização das atividades), para fazer predominar aquele sistema. (PRADO JÚNIOR, 1976, p.120).

Bonfim tece reflexões acerca da influência do parasitismo no contexto de exploração do colono branco sobre o escravo negro provedor de mão de obra:

Em certos casos, se o parasitismo feroz de um grupo sobre outro não produz o aniquilamento deste último, trazendo como resultado final o aniquilamento total da sociedade, é porque o grupo explorador conseguiu renovar a sua provisão de vítimas. Tal é a história da escravidão no Brasil e nas outras partes da América. Os pobres pretos eram literalmente devorados pelo chicote, sacrificados pela alimentação insuficiente e pelo excesso de trabalho. (BONFIM, 2008, p. 83)

Caio Prado Júnior argumenta em Evolução Política do Brasil, como o modo de produção capitalista e o conservadorismo político influenciou o panorama que resultará na manutenção do patriarcado rural: 
A evolução política progressista do Império corresponde assim, no terreno econômico, à integração sucessiva do país numa forma produtiva superior: a forma capitalista. As instituições primitivas como a escravidão, herdadas da antiga colônia, são varridas pelas novas forças produtivas que vão se formando e desenvolvendo no correr do século passado. Não é somente com o trabalho servil que isto se dá. O espírito conservador-retrógrado, que representa os interesses ligados à reação anti-progressista, tinha-se encastelado numa série de instituições políticas, como o Senado vitalício e o Conselho de Estado, onde, pela natural imobilidade delas, freava a cada passo a marcha do país. (PRADO JÚNIOR, 2004, p. 96).

A persistência desse tipo de mão de obra - 30\% da população era de escravos, mais um expressivo número de indivíduos desprovidos de bens e subsistindo num nível de vida material ínfimo - não se alterou de maneira significativa com a Abolição, sendo evidente a concentração de extrema riqueza que caracteriza a economia colonial e se manteve até os fins do século XIX, fato observado por Caio Prado Júnior:

Mas índice apenas, e não o mal originário em si, o que é bom notar porque nem sempre foi lembrado, como não o foi pelos idealistas da Abolição, que libertando o escravo, pensaram em realizar outra coisa mais que uma simples modificação do estatuto jurídico e nominal do trabalhador. O que mantinha a massa da população brasileira naquele grau ínfimo de existência material e em consequência moral, que era o seu, não era somente a escravidão, mas antes a organização fundamental do país, de que o trabalho escravo não é senão um dos aspectos, que, abolido, se substitui por outro que continuou, com pouca diferença, mantendo o trabalhador e portanto a massa da população naquele nível de existência. (PRADO JÚNIOR, 1976, p. 124).

O coronelismo se instituiu, assim, plasmando várias dessas características num contexto de aliança com o governo, baseando-se na troca de favores, sendo o voto, nesse contexto uma forma de possessão, uma verdadeira marca dos eleitores por parte de seus respectivos chefes políticos. Um coronel bem sucedido era um elemento socioeconômico polarizador, que operava como um ponto de referência que possibilitava aos indivíduos sob a égide do chefe político reconhecer sua posição no espaço social. Esse relacionamento baseado na troca de favores e na influência fica evidente no raciocínio de André Heráclio do Rego:

$\mathrm{Na}$ estrutura do coronelismo, somente os indivíduos possuidores de relativa fortuna, hereditária ou adquirida, eram capazes de trocar favores e de obter uma clientela; paralelamente à fortuna, entretanto, 
as qualidades pessoais permitiam ao indivíduo elevar-se à posição de chefe. Assim, do pequeno chefe político provinciano ao grande chefe nacional, os coronéis possuíam essa virtude que Max Weber denomina carisma, e que considera como a virtude dos caudilhos. A liderança dos coronéis possuía dessa forma um aspecto carismático, e não somente tradicional, pois o eleito somente seria um grande chefe se provocasse a adesão afetiva e entusiástica dos homens, deles conseguindo uma obediência espontânea, qualidade essa que reforçava a solidariedade interna do grupo. (REGO, 2008, p. 67).

Outro aspecto importante a se notar na dinâmica operacional do coronelismo é seu embasamento familial, sendo o coronel um chefe de parentela. Sérgio Buarque de Holanda argumenta, em seu estudo, sobre como o patriarcado rural influenciou o paradigma de formação das instituições políticas nacionais:

[...] as facções (políticas) são constituídas a semelhança das famílias, precisamente das famílias de estilo patriarcal, onde os vínculos biológicos e afetivos que unem ao chefe os descendentes colaterais e afins, além da famulagem e dos agregados de toda sorte, hão de preponderar sobre as demais considerações. Formam, assim, como um todo indivisível, cujos membros se acham associados, uns aos outros, por sentimentos e deveres, nunca por interesses ou ideias. (HOLANDA, 1956, p. 98).

Desta maneira, a família patriarcal se via intimamente associada ao processo de construção das estruturas de poder no Brasil, que se torna difícil o estudo da primeira sem uma inter-relação com essas estruturas, sejam os partidos políticos propriamente ditos ou o mandonismo e seus diversos aspectos, o que inclui o coronelismo. Caio Prado Júnior, no entanto, chama a atenção para se encarar o papel da família de uma perspectiva dialética, visto a escassez numérica de indivíduos desta a nível geral, bem como o seu próprio status como instituição:

A formação brasileira, ao contrário do que se afirma correntemente, não se processou, salvo no caso limitado e como veremos, deficiente, das classes superiores da "casa-grande", num ambiente de família. Não é isto o que ocorre com a massa da população: nem com o colono recém-chegado, nem com o escravo, escusado acrescentá-lo; talvez ainda menos com esta parte da população livre, econômica e socialmente instável que temos já visto sob outros aspectos, e à qual falta base sólida em que se assentar a constituição da família. (PRADO JÚNIOR, 1976, p. 351).

O autor paulista afirma em nota a este trecho a rarefação de indivíduos pertencentes a uma família, que por si só é uma classe superior elevada de maneira que "ser de família, entre nós, constituía um distintivo de superioridade, de quase 
nobreza", questionando assim alguns estereótipos formados sobre o papel da família brasileira.

\section{GAMONALISMO E CORONELISMO}

Apesar de apresentar suas características particulares, o gamonalismo - e é importante lembrar outros fenômenos sociais, políticos e econômicos como o caudilhismo e o caciquismo mexicano, possui muitas similaridades com as várias modalidades de mandonismo comuns no Brasil, sendo localizado em território andino. O gamonalismo pode ser descrito como uma estrutura de poder descentralizada que se baseia na segmentação do funcionamento da sociedade agrária, caracterizado pela questão do poder regional e local como forma de controle a grupos étnicos, como os povos indígenas. José Carlos Mariátegui discorre acerca da ameaça do feudalismo dos gamonales para os interesses indígenas:

O problema indígena já não admite a mistificação a que perpetuamente o submeteu uma turba de advogados e literatos, consciente ou inconscientemente mancomunados com o interesse da casta latifundiária. A miséria moral e material da raça indígena aparece muito claramente como uma simples consequência do regime econômico e social que sobre ela pesa há séculos. Esse regime sucessor do feudalismo colonial é o gamonalismo. Sob seu império, não se pode falar seriamente de redenção do índio. (MARIÁTEGUI, 2010, p. 54, grifos do autor).

Assim, fica evidente uma semelhança com a transição de estrutura do patriarcado rural que se manteve com o advento do coronelismo. A questão indígena é um ponto específico do gamonalismo, que lhe dá características particulares. Mariátegui fala de como a organização social dos índios andinos foi vital para a exploração e escravização desses pelos proprietários rurais, o que foi inicialmente explorado pelos jesuítas:

Somente os jesuítas, com seu positivismo orgânico, puderam mostrar, no Peru, como em outras terras da América, a aptidão para a criação econômica. Os latifúndios que lhes foram destinados prosperaram. Os vestígios de sua organização ficaram como uma marca duradoura. Quem se lembra da vasta experiência dos jesuítas no Paraguai, onde habilmente aproveitaram e exploraram a tendência natural dos indígenas para o comunismo, não pode se surpreender que essa congregação de filhos de São Inigo de Loyola, [...] fossem capazes de criar o solo peruano centros de trabalho e produção que os 
nobres, doutores e clérigos, dedicados em Lima a uma vida fácil e sensual, jamais se preocuparam em formar. (MARIÁTEGUI, 2010, p. 35).

Essa afirmação é consistente com o que diz Caio Prado Júnior, ao argumentar que o baixo nível de desenvolvimento social dos índios em território brasileiro desestimulou o seu emprego como mão de obra escrava:

Utilizaram-se a princípio os autóctones. Lá onde sua densidade é grande, e onde estavam habituados a um trabalho estável e sedentário, como no México e no altiplano andino, o escravo ou semi-escravo indígena formará o grosso da mão-de-obra. No Brasil ele é mais escasso, e sobretudo ineducado para o sistema de trabalho organizado que exige a agricultura colonial. Empregou-se na falta de melhor, particularmente naquelas regiões de nível econômico mais baixo que não comportavam o preço elevado do escravo africano. (PRADO JÚNIOR, 1976, p. 122).

Argumentação de certa forma semelhante é alcançada por Bonfim, ao teorizar sobre como a exploração do indígena foi práxis geral em todo território latinoamericano, estimulada pela avidez de enriquecimento fácil dos colonos que se estabeleceram na América Latina, bem como sua incompatibilidade com o trabalho pacífico:

\footnotetext{
Esgotados os tesouros já feitos, adotaram o processo sumário de escravizar os naturais e enriquecer à custa deles, com o seu labor. Os governos, por sua vez, arranjaram logo a máquina administrativa de modo a sugar a colônia o mais possível. Não havia outra preocupação. Os territórios e os privilégios eram dados ou vendidos segundo os interesses da corte ou dos seus representantes. Senhor do território, apossado da mina, o colono só pensava em arrancar deste eldorado o máximo de riqueza, no menor prazo possível. Para isto ele era livre de empregar os processos que quisesse, contanto que o fisco contasse com a sua parte. Português ou espanhol, ele vinha para entesourar e não para trabalhar; e era logo a caça implacável ao índio. Sob a desculpa de que eram antropófagas algumas tribos, a metrópole estabeleceu a venda dos índios capturados - estava normalizado o cativeiro, estava sistematizado o parasitismo, na sua forma ideal: uns a trabalhar e outros a engordar e a gozar. Assim se completou a perversão da vida econômica nas novas sociedades. Tendo provado o fruto do trabalho escravo, os colonos não voltariam mais atrás; onde o elemento índio era escasso ou onde ele foi exterminado, logo o substituíram pelo escravo africano. (BONFIM, 2008, p. 89).
}

Mariátegui fala sobre a diferença de configurações econômicas no território da América do Sul, afirmando que países situados na costa do Atlântico teriam sido melhor favorecidos pelo tráfico: 
A Argentina e o Brasil, principalmente, atraíram para o seu território capitais e imigrantes europeus em grande quantidade. Aluviões ocidentais, fortes e homogêneos, aceleraram nesses países a transformação da economia e cultura, que adquiriram gradualmente a função e a estrutura da economia e da cultura europeias. A democracia burguesa e liberal pôde lançar ali raízes seguras, enquanto o resto da América do Sul isso era impedido pela subsistência de tenazes e extensos resíduos de feudalismo. (MARIÁTEGUI, 2010, p. 38).

Embora retrate um panorama verídico, que é o da distância do Peru e outros países em relação a centros europeus, a afirmação de Mariátegui deve ser relativizada e encarada de maneira dialética, uma vez que ignora os processos ocorridos no Brasil de manutenção de estruturas de poder associadas ao clientelismo, tais como os já referidos mandonismo e coronelismo. Não obstante, muitas das características de que fala Mariátegui acerca dos gamonales podem ser identificada com aquelas dos coronéis:

O juiz, o subprefeito, o comissário, o professor, o coletor, estão todos enfeudados à grande propriedade. A lei não pode prevalecer contra os gamonales. O funcionário que se empenhasse em impô-la seria abandonado e sacrificado pelo poder central, junto ao qual são onipotentes as influências do gamonalismo, que atuam diretamente por meio do parlamento, por uma ou outra via com a mesma eficiência. (MARIÁTEGUI, 2010, p. 55).

Ficam evidentes as similaridades entre as práticas de domínio político, social e econômico entre os coronéis e gamonales. Sérgio Buarque de Holanda endossa esse cenário ao falar sobre a influência dos patriarcas rurais sobre os estratos políticos, econômicos, legislativos e sociais:

A família patriarcal fornece, assim, o grande modelo por onde hão de calcar, na vida política, as relações entre governantes e governados, entre monarcas e súditos. Uma lei moral inflexível, superior a todos os cálculos e vontades dos homens, pode regular a boa harmonia do corpo social, e portanto deve ser rigorosamente respeitada e cumprida. (HOLANDA, 1956, p.110).

\section{REPRESENTAÇÕES NA FICÇÃO}

Os romances de José Lins do Rego ficcionalizam estas estruturas de poder mormente aqueles que compõem o ciclo da cana de açúcar - sob um viés memorialista e autobiográfico, dada a identificação de vários dos personagens com 
familiares do autor paraibano, e dele próprio (o personagem Carlos de Melo, protagonista em Menino de Engenho (1932), Doidinho (1933) e Banguê (1934) tem íntima relação com o próprio José Lins do Rego). Outros personagens como o Coronel Lula de Holanda, e o Capitão Vitorino Carneiro da Cunha - o Papa Rabo, são homônimos de indivíduos de carne e osso que foram próximos da família do autor e desempenham na fiç̧ão papeis bem parecidos com os que são relatados no livro de memórias (Meus Verdes Anos, 1956) e nas crônicas do autor, como Gordos e Magros (1942) e Homens, Seres e Coisas (1952). Este trecho da obra Menino de Engenho (1943) ilustra bem essa representação do senhor de engenho, do coronel, através do Coronel José Paulino, o avô do protagonista Carlos de Melo:

O Santa Fé ficava encravado no engenho do meu avô. As terras do Santa Rosa andavam léguas e léguas de norte a sul. $O$ velho José Paulino tinha este gosto: o de perder a vista nos seus domínios. Gostava de descansar os olhos em horizontes que fossem seus. Tudo o que tinha era para comprar terras e mais terras. Herdara o Santa Rosa pequeno, e fizera dele um reino, rompendo os seus limites pela compra de propriedades anexas. Acompanhava 0 Paraíba com as várzeas extensas e entrava de caatinga adentro. la encontrar as divisas de Pernambuco nos tabuleiros de Pedra de Fogo. Tinha mais de três léguas, de estrema a estrema. $E$ não contente de seu engenho possuía mais oito, comprados com os lucros da cana e do algodão. Os grandes dias de sua vida, Ihe davam escrituras de compra, os bilhetes de sisa que pagava, os bens de raiz, que the caíam nas mãos. Tinha para mais de quatro mil almas debaixo de sua proteção. Senhor feudal ele foi, mas os seus párias não traziam a servidão como um ultraje. (REGO, 1986, p. 105).

Antônio Cândido analisa a ficcionalização das estruturas de poder comuns ao coronelismo nas obras do autor paraibano, por meio do que ele chama de "romance de grandes personagens, que se sobrepõem e se cruzam":

Ao alto, o velho José Paulino, do Santa Rosa, deus ex machina nas questões dos parentes, dominando serenamente a Várzea com sua estatura de rico senhor de sete engenhos, chefe político do governo, não pagando impostos com a tranquilidade de quem desfruta um privilégio, alvo das invejas de uns, da oposição aberta de outros. A sua ação se organiza dentro do antigo código patriarcal, ainda permitido graças às condições econômicas sobre que se assenta autoridade do velho senhor. As relações entre os parentes são reguladas por ele, e acorrer às suas dificuldades é um dever de patriarca a que ele nunca foge. A sua voz é ouvida pelas autoridades policiais; o governo atende os seus pedidos; o cangaceiro Antônio Silvino acata os seus desejos, porque estabeleceu com ele um modus vivendi. O seu prestígio garante a sua autoridade; a sua riqueza garante o seu prestígio. (CÂNDIDO, 2011, p. 58). 
Alguns aspectos do gamonalismo podem ser observados no romance do autor peruano Manuel Scorza, Redoble por Rancas (1970), aonde o autor narra a prática de um líder político relacionado ao gamonalismo, a exigir a virgindade das filhas de seus subordinados, "suas afilhadas", quando estas completavam 15 anos:

Don Migdonio de la Torre, altanera atalaya de músculos rematada en una cabeza española quemada por barbas imperiales, prefirió consolarse con la versión de sus títulos. Ni sus límites extraviados en tres climas, ni los avatares de las cosechas, ni los engordes de la ganadería le interesaban. Lo único que encendía sus azules ojos eran sus «ahijaditas». Las tenía por cientos. Todas las hijas de su peonada le pertenecían. A los dudosos honores de una enaduría reiteradamente ofrecida, prefería la llanura de plumas de su gigantesca cama parada sobre cuatro empotradas garras de águila. Un disecado cóndor abría alas inmensas sobre su insomnio. $\mathrm{Ni}$ el Libro de Cuentas de la Tienda de Raya, ni el Registro de la Ganadería, ni el Mayor, ni el Menor, donde constaban sus abundancias, lo absorbía como el Libro de los Nacimientos. Ansiosamente hojeaba el registro donde se anotaba la fecha de nacimiento de cada una de las niñas nacidas en El Estribo. El día que cumplían quince años se las levaban a la cama para que las mejorara. No era, desde luego, una novedad en las haciendas. Lo que se desconocía era la mitológica fuerza de su tercera pierna. Era inagotable. No le bastaban cinco muchachitas diarias y una vez, tras derrengar a la putería de un burdel de Huánuco, salió a empapar las flores con níveo rocío. Era colossal. (SCORZA, 1970, p. 45).

Em outro trecho, o mesmo Don Migdonio executa vários de seus empregados, envenenando-os através de bebida oferecida a eles, por motivo de requisitarem formar um sindicato:

—¿Qué quieren, hijos? -preguntó don Migdonio afablemente.

Espíritu sintió paludismo en las rodillas.

-Patrón, yo...

-Mira, Félix, para que no sufras te diré de una vez que yo no me opongo al sindicato. No hay inconveniente —dijo con la misma sencillez con que hubiera podido autorizar: «beban no más del río» 0 «pueden orinar en descampado»-. No, no me opongo; por el contrario, los felicito. Yo quiero que la hacienda progrese y cambie. ¡Vamos a celebrarlo!

Y se volvió a un sirviente.

-Oye, tráeme la garrafa de aguardiente del comedor .

El sirviente — ¡había cerrado los ojos de don Medardo!— salió sin ocultar el asco que le

merecía la apoteosis de la ingratitud. Volvió con la garrafa y sirvió las copas.

—Yo brindaré con la pura copa. Anoche me excedí —dijo jovialmente don Migdonio-. 
Bueno, muchachos, jsalud!

Para escapar a los remolinos del delirio se zamparon de un trago las copas. Don Migdonio mandó rebosárselas de nuevo.

Vaciaron la segunda copa.

—No sé qué tengo — dijo Jaramillo llevándose las manos a la garganta-, me falta el aire.

-Algo me ha caído mal —susurró Madera, lívido, torciéndose sobre el vientre.

Fue el primero en derrumbarse. Rodaron otros tres fulminados y los demás revueltos en

un agónico retorcimiento de tripas. Don Migdonio los abarcó con una mirada de cuero.

Comprendiéndolo demasiado tarde, Rico, en el espasmo, derribó el retrato de la madre de

don Migdonio; pero ya no pudo escupir sobre él.

- ¡Hijo de puta...! —alcanzó a decir Espíritu Félix antes de chorrearse con las tripas

tostadas por el veneno. (SCORZA, 1970, p. 47).

\section{CONCLUSÃO}

O coronelismo brasileiro e o gamonalismo peruano são estruturas de poder local baseadas no poder político descentralizado, e ao mesmo tempo remetem a uma redefinição de decadência do patriarcado rural de molde feudal e aumento do poder público. As duas modalidades apresentam diversas similitudes mas, por outro lado, carregam suas peculiaridades específicas Ambas estão relacionadas a um passado de exploração e parasitismo social, econômico e ideológico, aonde as práticas de exploração da colônia sobre a metrópole foram se transfigurando e se perpetuando a nível cada vez mais local.

O coronelismo está ligado a um formato que adquiriu o mandonismo no âmbito específico do Nordeste brasileiro, ligado à grande propriedade e ao trabalho semi-escravo, em parte possibilitado por contingentes de escravos libertos que não tinham alternativa senão continuar com seus senhores, ou senhores de seus pais. Tem características que incluem a grande propriedade, a lavoura monocultural, e a figura carismática do líder político; o senhor de engenho ou coronel, que mantinha uma grande quantidade de protegidos políticos e assegurava sua hegemonia através da instituição histórica da família patriarcal em setores estratégicos de âmbito político, social e econômico no país, bem como a troca de favores com o poder público quando de sua decadência e concomitante ascensão do referido poder, o que paradoxalmente manteve o seu status de dominação e exploração. 
O gamonalismo está igualmente ligado à grande propriedade rural e monocultural, mas está embasado ao trabalho escravo indígena, e à manutenção dessa escravidão (ou semi-escravidão), quando da instituição política dos gamonales, que teve uma configuração política diferente da encontrada no fenômeno sócio-político brasileiro, uma vez que a legislação da república - com a instituição do Vice-Reinado em âmbito peruano, favoreceu os latifúndios, possibilitando-os legalmente de absorver as propriedades indígenas. A organização social do povo indígena andino, com tendências naturais para o socialismo, favorecia o seu emprego nas grandes propriedades monocultoras, diferentemente do que ocorreu no Brasil, aonde o baixo nível de organização e desenvolvimento social dos indígenas locais (bem como o seu número reduzido) desestimulou o seu emprego como mão de obra em detrimento ao escravo negro africano - que também é motivo da proximidade brasileira com as rotas de tráfico negreiro - salvo em localidades aonde o baixo nível de recursos assim o exigisse.

Ambos os fenômenos, que junto a vários outros similares por toda a América Latina nortearam as estruturas de poder político no período de transição das monarquias para repúblicas, encontraram ecos em obras literárias, como a de Manuel Scorza ao retratar o gamonalismo em sua ficção. No caso brasileiro é evidente a contribuição de José Lins do Rego, com seus romances que retratam a decadência do patriarcado rural dos senhores de engenho frente à modernização proporcionada pelas usinas, assim como demonstram o modus operandi desses coronéis como indivíduos que se mantinham em postura hegemônica através da troca de favores com o poder público e do apadrinhamento político de seus protegidos. O relato das estruturas de poder nessas obras de ficção é vital para a compreensão destes fenômenos sócio-políticos, tão caros ao entendimento da formação das diversas sociedades latino-americana.

\section{REFERÊNCIAS}

BONFIM, Manoel. A América Latina: males de origem. Rio de Janeiro: Centro Eldestein, 2008.

CÂNDIDO, Antônio. Brigada Ligeira. Rio de Janeiro: Ouro sobre Azul, 2011.

FREYRE, Gilberto. Nordeste: Aspectos sobre a influência da cana sobre a vida e a paisagem do Nordeste do Brasil. São Paulo: Global, 2004. 
HOLANDA, Sérgio Buarque de. Raízes do Brasil. Rio de Janeiro: José Olympio, 1956.

MARIÁTEGUI, José Carlos. Sete ensaios da realidade peruana. São Paulo: Expressão Popular, 2010.

PRADO JÚNIOR, Caio. Formação do Brasil Contemporâneo. São Paulo: Editora Brasiliense, 1976.

. Evolução Política do Brasil. São Paulo: Companhia das Letras, 2004.

REGO, André Heráclio do. Família e Coronelismo no Brasil: uma história de poder. São Paulo: A Girafa Editora, 2008.

REGO, José Lins do. Ficção Completa. Rio de Janeiro: Editora Nova Aguilar, 1987. SCORZA, Manuel. Redoble por Rancas: Balada I. Barcelona: Planeta, 2008. 